\title{
ИССЛЕДОВАНИЕ РАСХОДА МАСЛА АВТОТРАКТОРНЫМИ ДВИГАТЕЛЯМИ
}

\author{
Б.С. Антропов (фото) \\ д.т.н., профессор, профессор кафедры автомобильного \\ транспорта \\ ФГБОУ ВО «Ярославский государственный технический \\ университет», г. Ярославль \\ В.В. Гуменный \\ доцент кафедры тактики и общевоенных дисциплин \\ В.В. Капралов \\ к.П.н., старший преподаватель кафедры тактики \\ и общевоенных дисциплин \\ В.А. Генералов \\ преподаватель кафедры тактики и общевоенных дисциплин \\ ФГБУ МО «Ярославское высшее военное училище \\ противовоздушной обороны», г. Ярославль
}

Общий расход масла, расход масла на долив (угар), пробег автомобиля, наработка двигателя в часах, замена масла

Total oil consumption, oil consumption for top-up (burning), vehicle mileage, engine hours, oil change

Определение количества расходуемого от замены до замены моторного масла находящимися в исправном состоянии автотракторными двигателями можно осуществить, используя следующую формулу:

$$
G_{M \Sigma}=\frac{V+G_{M g}}{\underline{T}}
$$

где $V$ - объём системы смазки, л;

$G_{M g}$ - количество масла на долив (угар) за период работы двигателя $T$; $\underline{T}$ - период работы двигателя от замены до замены (периодичность замены), ч.

Расход масла в л/ч характерен для тракторов и стационарных установок с ДВС (компрессоры, генераторы и т.п.). Расход масла на автомобилях обычно измеряется в расходе топлива в литрах на 100 км пройденного пути.

За наработку $\underline{T}$ автомобиль пройдёт путь:

$$
S=U_{\ni} \cdot \underline{T},
$$

здесь $U_{7}$ - эксплуатационная скорость автомобиля (с учётом работы двигателя на холостом ходу во время остановок по сигналам светофора, во время нахождения автомобиля в дорожных пробках и т.п.), км/ч.

Формулу расхода масла в литрах на 100 км можно получить, подставив в уравнение (1) значение $S$, умноженное на $10^{2}$ :

$$
G_{M \Sigma}=\frac{V+G_{M g}}{S} \cdot 10^{2} .
$$

Преобразуя уравнение (3), получаем следующее:

$$
G_{M \Sigma}=\frac{V}{S} \cdot 10^{2}+\frac{G_{M g}}{S} \cdot 10^{2} .
$$


Данная формула (4) состоит из суммы двух слагаемых. Первое - расход масла на замену, второе - расход масла на долив (угар). Первое слагаемое является постоянной величиной для одинаковых автомобилей (одной и той же модели, с одинаковым двигателем).

Второе слагаемое - величина переменная, возрастающая с увеличением пробега автомобиля и, как следствие, износом деталей цилиндропоршневой группы и уплотнительных элементов двигателя.

Таким параметром, как общий расход масла, на автомобильных предприятиях определяется необходимая потребность в масле для автомобилей всего парка на месяц, квартал, год.

Необходимую потребность автомобильных предприятий в моторном масле на год можно рассчитать по формуле:

$$
\begin{gathered}
G_{M \Sigma}=10^{-2} \cdot\left(G_{M \Sigma 1} \cdot S_{1}+G_{M \Sigma 2} \cdot S_{2}+\right. \\
\left.+\ldots G_{M \Sigma n} \cdot S_{n}\right),
\end{gathered}
$$

где $G_{M \Sigma n}$ - общий расход масла для двигателей $n$-ой модели, л/100 км;

$S_{n}$-суммарный пробег автомобилей $n$-ой модели за год, км.

Второе слагаемое формулы (4) (расход масла на долив (угар)) применяется для диагностирования состояния деталей цилиндропоршневой группы, а также является показателем экономичности автомобиля наравне с расходом топлива.

У новых автомобилей отечественного производства (перед вводом в эксплуатацию), с бензиновыми двигателями, технически исправных, расход масла на долив составляет $0.01 \div 0.02$ л/100 км.

Как правило, расход масла на долив (угар), обозначаемое для упрощения $G_{M}$ для автомобилей с дизельными двигателями определяется в процентах от израсходованного топлива, т.е.

$$
G_{M}=\frac{\Delta G_{M}}{\Delta G_{T}}
$$

где $\Delta G_{M}$ и $\Delta G_{T}$ являются абсолютным расходом масла и топлива за конкретный пробег $S$ (не менее 100 км) автомобиля.

Расход масла для новых, технически исправных автомобилей с двигателями ЯМЗ, будет составлять примерно $0,1 \div 0,5 \%$.

Значение $G_{M O}=0,1 \%$ имеют 4- и 6-цилиндровые двигатели Ярославского моторного завода ЯМ3-534 и ЯМ3-536, с рядным расположением цилиндров, выпускаемые заводом с 2016 г. Размерность этих двигателей составляет $S / D=128$ мм $/ 105$ мм $[1,2]$.

Значение $G_{M O}=0,5 \%$ присуще 6- и 8-цилиндровым двигателям ЯМ3-236, 238 и их мо- дификациям. Размерность этих двигателей $S / D=140$ мм/130 мм. Зависимость расхода масла $G_{M}$ от пробега $S$ для двигателей ЯМ3-236, 238 и их модификаций показана на рисунке 1. Полученная зависимость выявлена в период испытаний двигателей на автомобилях МАЗ, осуществляющих дальние междугородние грузоперевозки, Ярославского $3 \mathrm{AO}$ «Межавтотранс».

Зависимость $G_{M}=f(S)$ :

$G_{M 0}=0,5 \%$ - расход масла в начальный период эксплуатации автомобиля;

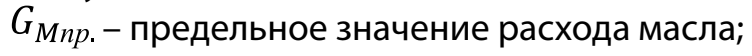

$S_{\mathrm{p}}$ - ресурс деталей цилиндропоршневой группы двигателя.

При достижении $G_{M n р}$. предельного значения, равного трёхкратному $G_{M 0}$, дальнейшая эксплуатация двигателей считается затратной. Как правило, в процессе эксплуатации на них полностью заменяют детали цилиндропоршневой группы (гильзы, поршни, поршневые пальцы).

Если во время замера расхода масла при пробеге $S_{i}$ выяснилось, что значение $G_{M i}$ больше нормы (при допуске $+5 \%$ ), т.е. не соответствует значению в точке "A» (рис. 1), то в этом случае существует необходимость проведения углубленного диагностирования деталей цилиндропоршневой группы, первым этапом которой является замер компрессии $P_{c}$ в цилиндрах двигателя.

К примеру, на двигателях ЯМЗ-236 и ЯМЗ-238 цилиндры считаются работоспособными, если $P_{c} \geq 2,5 \mathrm{M \Pi a}\left(25^{\mathrm{k}} / \mathrm{cm}^{2}\right)$. Меньшее значение $P_{c}$ может указывать на следующие дефекты в цилиндрах двигателя:

- повышенный износ деталей;

- разрушение колец и канавок поршней;

- задиры на зеркале цилиндров и поршней.

Последующим этапом диагностики цилиндров с низким значением $P_{c}$ служит проверка состояния гильз и поршней через отверстия под форсунки с помощью видеоскопа (осмотр состояния). Вероятные причины большого расхода масла рассмотрены в источниках [3, 4].

Эксплуатация двигателя с поломанными кольцами в дальнейшем приводит к нежелательным последствиям, а именно эрозионному разрушению перемычек между ними (рис. 2).

Процесс разрушения перемычек происходит следующим образом: в местах поломки колец на такте «рабочий ход» начинают с высокой температурой прорываться газы; прорыв их в картер двигателя происходит с высокой скоростью, что, в конечном счёте, через определённый промежу- 


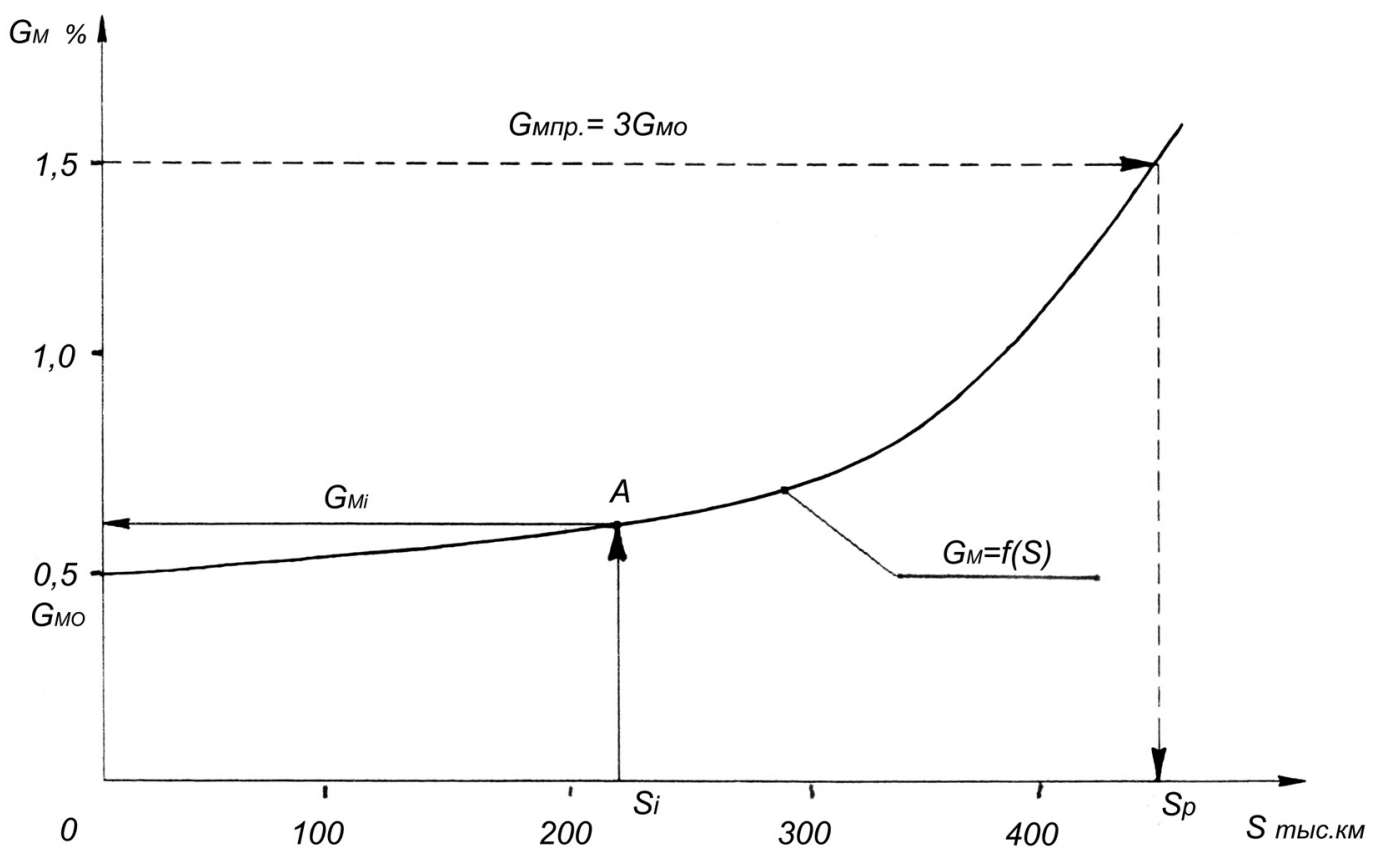

Рисунок 1 - Зависимость расхода масла от пробега

ток времени приводит к эрозии (размыванию) металла (сплава алюминия АЛ-30) в месте прорыва.

На двигателях с данной неисправностью резко снижается мощность, возрастает расход масла и топлива, а также из сапуна увеличивается выброс большого количества картерных газов.

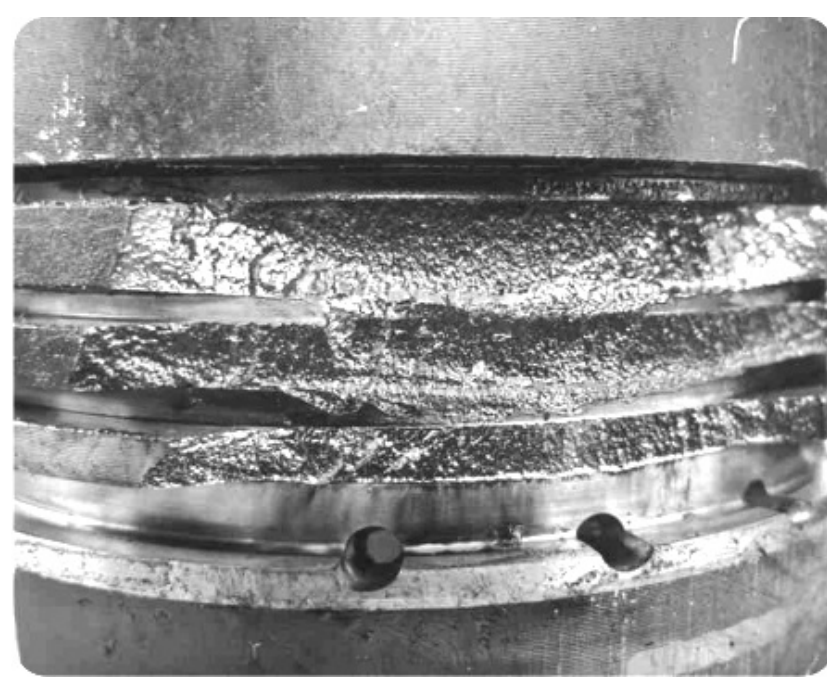

Рисунок 2 - Эрозионное разрушение перемычек поршня

\section{Bывод}

Установлено, что расход масла является величиной переменной, возрастающей по мере увеличения пробега двигателя, вследствие износа деталей цилиндропоршневой группы ДВС. Установлено также, что при предельном расходе масла, составляющим тройное увеличение заводского норматива для новых двигателей (перед запуском их в эксплуатацию), эксплуатация должна быть прекращена по экономическим соображениям. Как правило, в данном случае на двигателях заменяются детали цилиндропоршневой группы (поршни, гильзы и поршневые кольца). Расход масла на долив используется и для диагностирования двигателей, а именно по его значению можно определить состояние деталей цилиндропоршневой группы.

Изложенные в статье методы определения расхода масла двигателя и их применение для оценки состояния деталей цилиндропоршневой группы могут быть использованы специалистами конструкторских бюро при проектировании и испытании двигателей в заводских условиях, инженерно-техническими работниками, занятыми в сфере технического обслуживания и ремонта автомобильной техники, а также в учебном процессе при подготовке специалистов по эксплуатации автомобильного транспорта. 


\section{Лumepamypa}

1. Двигатели ЯМЗ-534 и их модификации. Руководство по эксплуатации 5340.3902150РЭ [Текст]. Ярославль: ОАО «Автодизель», 2011. - 158 с.

2. Двигатели ЯМЗ-536 и их модификации. Руководство по эксплуатации 536.3902150РЭ [Текст]. - Ярославль: ОАО «Автодизель» (ЯМЗ), 2013. - 240 с.

3. Антропов, Б.С. Диагностирование автотранспортных средств [Текст]: монография / Б.С. Антропов, И.С. Басалов. - Ярославль: Издательский дом ЯГТУ, 2016. - 144 с.

4. Чернышев, Г.Д. Фильтрация воздуха - важнейший из путей повышения ресурса ДВС [Текст] / Г.Д. Чернышев, Е.П. Слабов, Б.С. Антропов // Автомобильная промышленность. - 2000. - № 6. - С. 20-22.

\section{References}

1. Dvigateli JaMZ-534 i ih modifikacii. Rukovodstvo po jekspluatacii 5340.3902150RJe [Tekst]. - Jaroslavl': OAO «Avtodizel'», 2011. - $158 \mathrm{~s}$.

2. Dvigateli JaMZ-536 i ih modifikacii. Rukovodstvo po jekspluatacii 536.3902150RJe [Tekst]. - Jaroslavl': OAO «Avtodizel'» (JaMZ), 2013. - $240 \mathrm{~s}$.

3. Antropov, B.S. Diagnostirovanie avtotransportnyh sredstv [Tekst]: monografija/B.S. Antropov, I.S. Basalov.Jaroslavl': Izdatel'skij dom JaGTU, 2016. - $144 \mathrm{~s}$.

4.Chernyshev, G.D. Fil'tracija vozduha - vazhnejshij iz putej povyshenija resursa DVS [Tekst]/G.D.Chernyshev, E.P. Slabov, B.S. Antropov // Avtomobil'naja promyshlennost'. - 2000. - № 6. - S. 20-22.

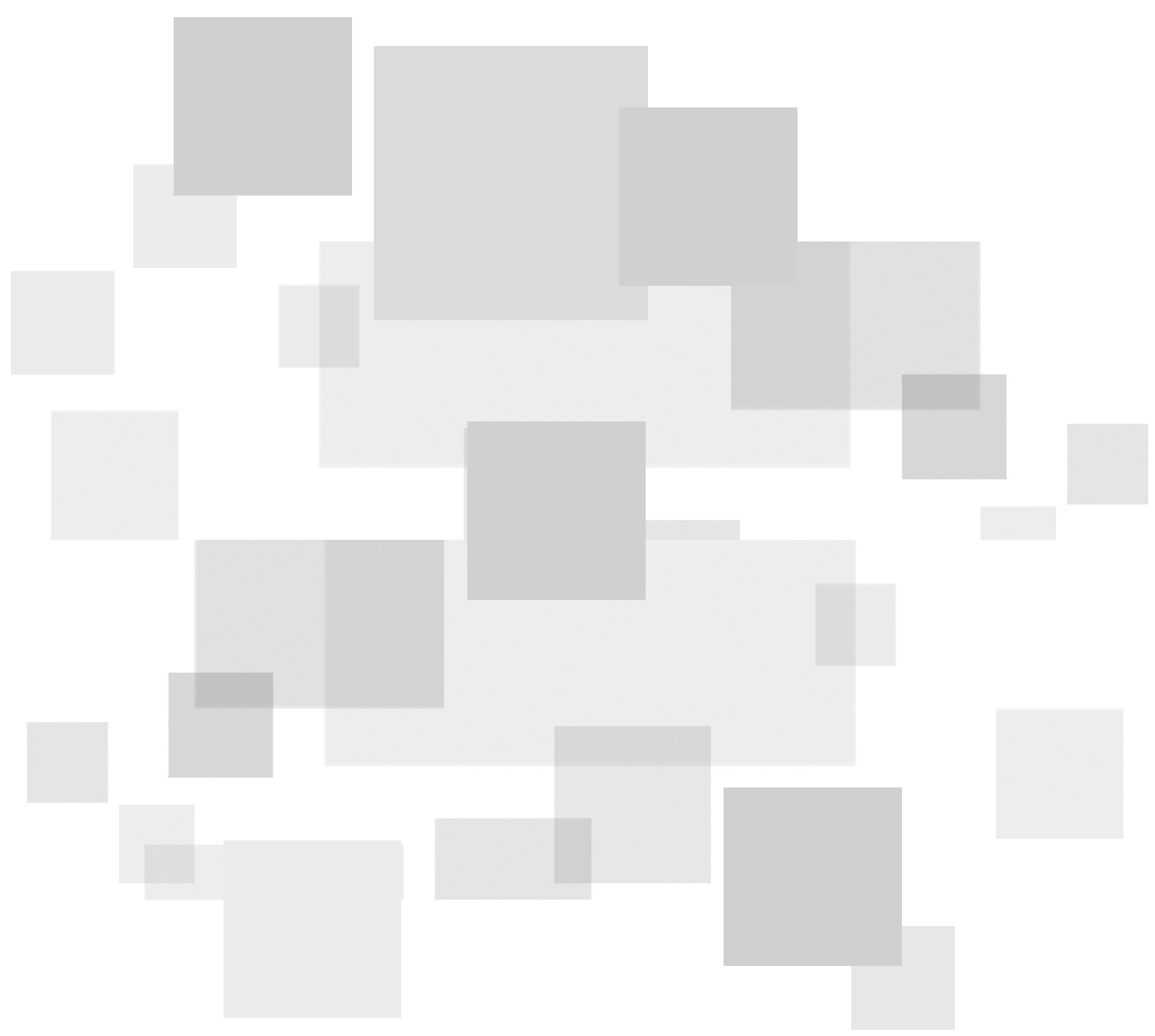

